\title{
CONTENTS BY KEYWORD
}

Biomaterials

Cellular materials

Characterization methods

Composite materials

Corrosion and oxidation

Mechanical properties

Metals and alloys

Microstructure

Nanomaterials

Porosity

Viscoelasticity
Designing biological apatite suitable for neomycin delivery

R. Murugan et al.

4343

Structure and mechanical properties of micro and macro balloons: An overview

of test techniques . . . . . . . . . . . . .

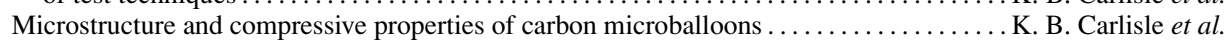

Characterization of epoxy syntactic foams by dynamic mechanical analysis . .

S. Sankaran et al.

3961

3987

4041

Structure and mechanical properties of micro and macro balloons: An overview

of test techniques . . . . . . . Carlisle et al.

3961

Characterization of epoxy syntactic foams by dynamic mechanical analysis ..............S. Sankaran et al. 4041

A new indirect method of measuring the contents of solid inclusions in liquid

Fibre-reinforced composite implant: in vitro mechanical interlocking with bone model material and residual monomer analysis ...............
esigning biological apatite suitable for neomycin delivery.

Designing biological apatite suitable for neomycin delivery $\ldots \ldots \ldots \ldots \ldots \ldots \ldots \ldots \ldots$. Murugan et al.

Structure and mechanical properties of micro and macro balloons: An overview of test techniques . . . . . Carlisle et al.

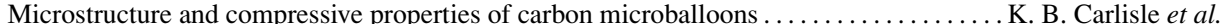
Fibre-reinforced composite implant: in vitro mechanical interlocking with bone model material and residual monomer analysis

R. H. Mattila et al.

Corrosion and stress corrosion cracking behavior of equal channel angular pressed oxygen-free copper in $3.5 \% \mathrm{NaCl}$ solution

Designing biological apatite suitable for neomycin delivery

R. Murugan et al.

A new indirect method of measuring the contents of solid inclusions in liquid aluminium alloys

Microstructure and compressive properties of carbon microballoons

K. B. Carlisle et al.

Corrosion and stress corrosion cracking behavior of equal channel angular pressed oxygen-free copper in $3.5 \% \mathrm{NaCl}$ solution

Corrosion and stress corrosion cracking behavior of equal channel angular pressed oxygen-free copper in $3.5 \% \mathrm{NaCl}$ solution

Y. H. Jang et al.

Fibre-reinforced composite implant: in vitro mechanical interlocking with bone model material and residual monomer analysis

R. H. Mattila et al.

Designing biological apatite suitable for neomycin delivery R. Murugan et al.

4321

Characterization of epoxy syntactic foams by dynamic mechanical analysis

S. Sankaran et al. 